\title{
To study the outcome of exchange transfusion in severe neonatal sepsis in neonates admitted in NICU at Dr. Bhim Rao Ambedkar memorial hospital, Raipur, Chhattisgarh, India
}

\author{
Narayan Rao B. ${ }^{1}$, Dewangan $5^{2}{ }^{2}$, Kumar Singh V. ${ }^{3 *}$ \\ DOI: https://doi.org/10.17511/ijpr.2021.i03.05
}

${ }^{1}$ Badri Narayan Rao, Associate Professor, Department of Paediatrics, Pt. J.N.M. Medical College, Raipur, Chhattisgarh, India.

2 Shashikant Dewangan, Assistant Professor, Department of Paediatrics, Pt. J.N.M. Medical College, Raipur, Chhattisgarh, India.

3* Vikas Kumar Singh, Postgraduate, Department of Paediatrics, Pt. J.N.M. Medical College, Raipur, Chhattisgarh, India.

Background: Sepsis is one of the most common causes of neonatal mortality and morbidity. Immaturity of the immune system, newborn infants are highly susceptible to systemic infection. Blood exchange transfusion in severe neonatal sepsis remove bacteria, bacterial toxins, and circulating pro-inflammatory cytokines, improve perfusion and tissue oxygenation, correct the plasma coagulation system and enhance immunological defence mechanisms. Material and methods: This is a hospital-based, time-bound, analytical observational study conducted from January 2019 to December 2019 in the NICU of Dr. B.R.A.M. Hospital \& Pt. J. N. M. Medical College, Raipur, Chhattisgarh, India. The data was collected in pre-designed proforma, entered in Microsoft Excel and analysis was done using SSPS v 22.0. Result: About 42 neonates were diagnosed with severe neonatal severe. Of which $23(54.76 \%)$ were preterm, $42.24 \%$ were term neonates. Maximum 22 (52.38\%) were VLBW, 4.76\% were LBW and 19.05\% were with normal birth weight. In the study two-third of $28(66.67 \%)$ were outborn and one third were inborn. In the present study majority of $30(71.43 \%)$ had EOS and $12(28.57 \%)$ had LOS. In our study out of 42 study subjects $24(57.14 \%)$ died and $18(42.86 \%)$ were discharged after blood exchange transfusion. Of those who died $15(62.5 \%)$ were preterm and of those discharged $10(55.6 \%)$ were term neonates $(p=0.349)$. Outborn neonates more died as compare to inborn though this was also not significant $(p=0.133)$. Conclusion: significant reduction of mortality in patients who underwent exchange transfusion, together with the no adverse effects observed, suggest that this procedure should be considered for the treatment of neonates with severe sepsis.

Keywords: Neonatal sepsis, Exchange transfusion, Term neonates

Corresponding Author

Vikas Kumar Singh, Postgraduate, Department of Paediatrics, Pt. J.N.M. Medical College, Raipur, Chhattisgarh, India.

Email: drvikaskumarsingh90@gmail.com

\section{How to Cite this Article}

Rao BN, Dewangan S, Singh VK. To study the outcome of exchange transfusion in severe neonatal sepsis in neonates admitted in NICU at Dr. Bhim Rao Ambedkar memorial hospital, Raipur, Chhattisgarh, India. Pediatric Rev Int J Pediatr Res. 2021;8(3):152-159.

Available From

https://pediatrics.medresearch.in/index.php/ijpr/arti cle/view/679
To Browse

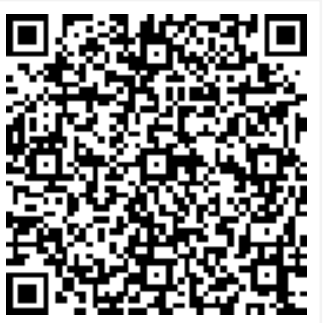




\section{Introduction}

As per World Health Organization (WHO) sepsis/infection is one of the most common causes of neonatal mortality and morbidity [1]. It has been estimated that $7.6 \mathrm{million}$ children younger than five years of age died in 2010; of these deaths, 64\% were attributed to infectious causes, and neonates contributed to a significant proportion (40.3\%)[2].

Owing to the immaturity of the immune system, newborn infants are highly susceptible to systemic infection [3-6]. Studies have demonstrated a significant deficit across both innate and adaptive immunity. Neonatal adaptive immune function is hampered by deficiencies in T-cell function and Bcell function (weak immunoglobulin production) and by underdeveloped secondary lymphoid tissues [3, $6]$. The innate immune system of these neonates is compromised by deficits in barrier integrity; circulating complement components; expression of antimicrobial proteins and peptides; quantitative and qualitative impairments in neutrophil, monocyte, macrophage, and dendritic cell functions; and decreased response to most Toll-like receptor agonists $[5,6]$.

The mortality rate can reach $60 \%$ in very low birth weight infants (VLBWI, birth weight < $1500 \mathrm{~g}$ ) [7]. Early diagnosis, timely administration of appropriate antibiotics, and proper supportive therapy are crucial to improve survival and reduce long-term sequelae $[8,9]$. Unfortunately, neonatal sepsis can progress rapidly to septic shock, occurring in $1.3 \%$ of neonates hospitalized in a neonatal intensive care unit (NICU), with an overall mortality of $40 \%$, reaching $71 \%$ in neonates weighing less than 1000 $\mathrm{g}$ at the onset of sepsis [10].

Case reports published in the medical literature in the 1970s [11, 12]. reporting the effective use of exchange transfusion (ET) in severe neonatal infection with sclerema prompted some authors to use this procedure as rescue therapy in neonates with severe sepsis in subsequent years [13-15]. The rationale for the use of ET using fresh, whole, adult blood is to remove bacteria, bacterial toxins, and circulating pro-inflammatory cytokines; to improve perfusion and tissue oxygenation; to correct the plasma coagulation system; and to enhance immunological defence mechanisms (increase in circulating levels of C3, immunoglobulins, improvement in the opsonic activity against the pathogen, enhancement of neutrophil function) [16-18].
Despite these potential benefits, very few studies were conducted in the last few decades to investigate the clinical efficacy of ET in neonatal sepsis and septic shock [16, 19-20]. Although most studies showed some beneficial effects to the use of $E T$, clear evidence for its clinical efficacy is lacking. The discrepancy observed across studies can be attributed largely to the use of different inclusion and exclusion criteria, diagnostic criteria, and study designs.

However there is a paucity of published studies and data on exchange transfusion on the outcome of neonatal sepsis cases particularly in developing countries. Therefore this prospective study was decided to conduct in a tertiary care teaching hospital in central India to measure the outcome of exchange transfusion in severe neonatal sepsis in term and preterm neonates.

\section{Primary Objectives:}

01 . To study mortality rate in severe neonatal sepsis undergoing exchange transfusion.

02. To compare the outcome of term and preterm neonates with severe sepsis undergoes exchange transfusion.

\section{Material and Methods}

Study design: This is a hospital-based, timebound, analytical observational study conducted from January 2019 to December 2019.

Study setting: This study was conducted in the NICU of Dr. B. R. A. M. Hospital \& Pt. J. N. M. Medical College, Raipur, Chhattisgarh, India.

Study duration: This study was conducted from January 2019 to December 2019.

Sample Size and Subject Selection: In this hospital-based time-bound analytical observational study, we enrol all neonates $>1000 \mathrm{gm}$ admitted with severe sepsis undergoing exchange transfusion to fulfil all criteria.

Inclusion criteria: Neonates weighing $>1000 \mathrm{gm}$ having sepsis with evidence of sclerema undergoing exchange transfusion.

\section{Exclusion criteria}

01. All neonates having severe sepsis with multiple congenital anomalies

02. All neonates having severe sepsis without sclerema

03. All neonates having severe sepsis with HIE 
04. All neonates having severe sepsis with RDS

05. All neonates having severe sepsis with MAS

06. All neonates having weight $<1000 \mathrm{gms}$

Major variable: Weight, Gestational age, Severe sepsis

Outcome variable: Mortality rate, Organ dysfunction, Duration of hospital stay, duration of antibiotic therapy, Adverse events during exchange transfusion

Data entry and analysis: Data entry was done in Excel and analysis was done using SPSS 20.0 software. Wherever, possible percentage, Chisquare test and logistic regression were applied.

\section{Methodology}

Neonatal sepsis defined as any sign and symptoms of bacteremia with any two or more of the following septic screening (WBC count $<5000 / \mathrm{mm} 3$, ANC < $1800 / \mathrm{mm} 3$, Immature to total neutrophil ratio $>0.2$, micro ESR $>15 \mathrm{~mm}$ in 1 st hour, CRP > $10 \mathrm{mg} / \mathrm{L}$. Signs and symptoms of bacteremia include hypothermia/hyperthermia, lethargy, poor cry, refusal to suck, poor perfusion prolonged capillary refill time, hypotonia, absent neonatal reflexes, bradycardia/tachycardia, respiratory distress, apnea, gasping respiration, hypoglycemia/hyperglycemia, metabolic acidosis.

Severe neonatal sepsis defined as neonatal sepsis with sclerema. Sclerema defined as diffuse hardening of subcutaneous tissue with minimal inflammation.

Those neonates that satisfied the inclusion criteria with severe sepsis enrolled and after obtaining written and informed consent from their parents/legal guardian, all basic demographic and clinical details recorded in a pre-designed proforma. Proforma contained information of neonates, gender, age, weight, DOB, DOA, GA, maturity, risk factors, vitals before and after exchange transfusion, investigation reports. Each neonate followed until the outcome (discharge from NICU or death).

\section{Results}

In our study around half of the study subjects were $23(54.76 \%)$ were preterm and the rest were term neonates. In the study two-third of 28 (66.67\%) were outborn and one third were inborn admissions who underwent exchange transfusion.
Majority 30 (71.43\%) had EOS and 12 (28.57\%) had LOS, in EOS 17 (40.48\%) had PROM, 5 (11.90\%) had > 3 vaginal exam and 3 (7.14\%) each had a maternal fever, foul-smelling discharge and uterine tenderness and $(40.48 \%)$ of neonates had prematurity/LBW as a risk factor for sepsis. Out of 42 study subjects 24 (57.14\%) have died and 18 $(42.86 \%)$ were discharged after exchange transfusion treatment. Of those who died 15 $(62.5 \%)$ were preterm and of those discharged 10 $(55.6 \%)$ were term neonates $(p=0.349)$. Outborn neonates more died as compare to inborn though this was also not significant $(p=0.133)$. Neonates who stayed for fewer days in hospitals had more dying as compared to those who stayed for longer duration and this was also statistically significant $(p=0.000)$. Morality in 2-5 days and 5-10 days of hospital duration was $100 \%$ and in more than 10 days it was $16.67 \%$. In our study out of 36 culturepositive samples $15(41.7 \%)$ were discharged after treatment and 21 (58.3\%) died. Of 36 culture positives maximum of 10 were positive for Klebsiella, 8 for E.coli, 6 each for $S$. aureus and $P$. aeruginosa, 4 were positive for Acinobactor and 2 were positive for Enterococcus. In present study maximum 32 (76.19\%) had cardiovascular dysfunction, $28(66.67 \%)$ had respiratory system dysfunction and 11 (26.19\%) had renal system dysfunction.

Table-1: Maturity of study subjects

\begin{tabular}{|l|l|l|}
\hline \multicolumn{1}{|c|}{ Maturity } & \multicolumn{1}{c|}{ Freq. } & \multicolumn{1}{c|}{ Percent } \\
\hline Preterm & 23 & 54.76 \\
\hline Term & 19 & 45.24 \\
\hline Total & 42 & 100 \\
\hline
\end{tabular}

Table 1 shows the maturity of study subjects. 23 $(54.76 \%)$ were preterm, $45.24 \%$ were term neonates.

Table-2: Type of admission of study subjects

\begin{tabular}{|l|l|l|}
\hline \multicolumn{1}{|c|}{ Type of admission } & \multicolumn{1}{c|}{ Freq. } & \multicolumn{1}{c|}{ Percent } \\
\hline Inborn & 14 & 33.33 \\
\hline Out born & 28 & 66.67 \\
\hline Total & 42 & 100 \\
\hline
\end{tabular}

Table 2 shows the type of admission of study subjects. $28(66.67 \%)$ were outborn and one third were inborn.

Table-3: maternal risk factors in study subjects

\begin{tabular}{|l|l|l|}
\hline \multicolumn{1}{|c|}{ Maternal risk factors } & \multicolumn{1}{|c|}{ Freq. } & \multicolumn{1}{|c|}{ Percent } \\
\hline PROM & 17 & 40.48 \\
\hline$>3$ vaginal exam & 5 & 11.90 \\
\hline
\end{tabular}


Rao B.N. et al: To study the outcome of exchange transfusion

\begin{tabular}{|l|l|l|}
\hline Maternal fever & 3 & 7.14 \\
\hline Foul smelling discharge & 3 & 7.14 \\
\hline Uterine tenderness & 2 & 4.76 \\
\hline Hyperleukocytosis & 2 & 4.76 \\
\hline No & 10 & 23.81 \\
\hline Total & 42 & 100 \\
\hline
\end{tabular}

Table 3 shows maternal risk factor in study subjects, 17 (40.48\%) had PROM, 5 (11.90\%) had $>3$ vaginal exam and $3(7.14 \%)$ each had maternal fever, foul smelling discharge and 2 (4.76\%) each had uterine tenderness, hyperleukocytosis.

Table-4: Treatment outcome of study subjects

\begin{tabular}{|l|l|l|}
\hline \multicolumn{1}{|c|}{ Outcome } & \multicolumn{1}{c|}{ Freq. } & \multicolumn{1}{c|}{ Percent } \\
\hline Death & 24 & 57.14 \\
\hline Discharged & 18 & 42.86 \\
\hline Total & 42 & 100 \\
\hline
\end{tabular}

Table 4 shows the treatment outcome of stud subjects, 24 (57.14\%) have died and 18(42.86\%) were discharged after treatment.

Table-5: Association b/w maturity and treatment outcome of study subjects

\begin{tabular}{|l|l|l|l|l|}
\hline \multirow{3}{*}{ Maturity } & \multicolumn{2}{|c|}{ Treatment outcome } & \multirow{2}{*}{ Total } & \multirow{2}{*}{ P-value } \\
\cline { 2 - 4 } & Death & Discharged & & \\
\hline \multirow{2}{*}{ Preterm } & 15 & 8 & 23 & 0.349 \\
\cline { 2 - 4 } & $65.2 \%$ & $34.8 \%$ & $100.0 \%$ & \\
\hline \multirow{2}{*}{ Term } & 9 & 10 & 19 & \\
\cline { 2 - 4 } & $47.4 \%$ & $52.6 \%$ & $100.0 \%$ & \\
\hline \multirow{2}{*}{ Total } & 24 & 18 & 42 & \\
\cline { 2 - 4 } & $57.1 \%$ & $42.9 \%$ & $100.0 \%$ & \\
\hline
\end{tabular}

Table 5 shows the association $b / w$ treatment outcome and maturity of study subjects, out of 23 preterm neonates 15 (65.2\%) died and 8 (34.8\%) were discharged after treatment and out of 19 term neonates 9 (47.4\%) died and 10 (52.6\%) were discharged after treatment.

Table-6: Association $b / w$ duration of hospital stay and treatment outcome of study subjects.

\begin{tabular}{|c|c|c|c|c|}
\hline \multirow[t]{2}{*}{ Hospital stay days } & \multicolumn{2}{|c|}{ Discha/death } & \multirow[t]{2}{*}{ Total } & \multirow[t]{2}{*}{$P$ value } \\
\hline & Death & Discharged & & \\
\hline \multirow[t]{2}{*}{$2-5$ days } & 13 & 0 & 13 & \multirow[t]{10}{*}{0.00} \\
\hline & $100.0 \%$ & $0.0 \%$ & $100.0 \%$ & \\
\hline \multirow[t]{2}{*}{ 5-10 days } & 8 & 0 & 8 & \\
\hline & $100.0 \%$ & $0.0 \%$ & $100.0 \%$ & \\
\hline \multirow[t]{2}{*}{$11-15$ day } & 2 & 7 & 9 & \\
\hline & $22.2 \%$ & $77.8 \%$ & $100.0 \%$ & \\
\hline \multirow[t]{2}{*}{$16-20$ days } & 1 & 4 & 5 & \\
\hline & $20.0 \%$ & $80.0 \%$ & $100.0 \%$ & \\
\hline \multirow[t]{2}{*}{$21-25$ days } & 0 & 5 & 5 & \\
\hline & $0.0 \%$ & $100.0 \%$ & $100.0 \%$ & \\
\hline
\end{tabular}

\begin{tabular}{|c|c|c|c|}
\hline \multirow[t]{2}{*}{$>25$ days } & 0 & 2 & 2 \\
\hline & $0.0 \%$ & $100.0 \%$ & $100.0 \%$ \\
\hline \multirow[t]{2}{*}{ Total } & 24 & 18 & 42 \\
\hline & $57.1 \%$ & $42.9 \%$ & $100.0 \%$ \\
\hline
\end{tabular}

Table 6 shows the association b/w hospital stay and treatment outcome of study subjects Association was tested using the chi-square test and it was statistically significant $(p=0.000)$.

Table-7: Organ dysfunction status in study subjects

\begin{tabular}{|l|l|l|}
\hline \multicolumn{1}{|c|}{ Organ system } & \multicolumn{1}{c|}{ Freq. } & \multicolumn{1}{c|}{ Percent } \\
\hline Cardiovascular & 32 & 76.19 \\
\hline Respiratory system & 28 & 66.67 \\
\hline Renal system & 11 & 26.19 \\
\hline
\end{tabular}

Table 7 shows the organ dysfunction status in study subjects, a maximum of 32 (76.19\%) had cardiovascular dysfunction, 28 (66.67\%) had respiratory system dysfunction and $11(26.19 \%)$ had renal system dysfunction.

\section{Discussion}

In our study around half of the study subjects were $23(54.76 \%)$ were preterm and the rest were term neonates. In our study the mean gestational age was $32 \pm 2.5$ weeks (range 30-38 weeks). Maximum 19 (45.24\%) had GA of 38-40 weeks, 11 (26.19\%) had GA of $32-34$ weeks and $9(2.43 \%)$ had GA of 34-36 weeks. Aradhya AS et al (2015) in Chandigarh reported the mean gestational age of neonates at exchange blood transfusion was $31 \pm 2.8$ weeks and $36 \%$ were small for their gestational age [20].

In a similar study Pugni, L et al. (2016) reported that the median gestational age was 28 weeks (range 26-31) weeks [21]. In our study two-third of $28(66.67 \%)$ were outborn and one third were inborn admissions who underwent exchange transfusion. In a similar study Pugni, L et al. (2016) reported that $88 \%$ of the neonates with severe sepsis were inborn admissions [21]. In most of the studies they have done the study on inborn newborns. Therefore the data were mostly reported for inborn.

In our study 17 (40.48\%) had PROM, 5 (11.90\%) had $>3$ vaginal exam and $(40.48 \%)$ of neonates had prematurity/LBW as risk factor for sepsis.In a similar study Aradhya AS et al (2015) in Chandigarh reported that $34 \%$ of mothers had pPROM ( $>24 \mathrm{~h}$ ) and $27 \%$ of mothers had pregnancy-induced hypertension [20]. 
This is suggestive that early preterm premature rupture is one of the major risk factors for sepsis in children. The onset of sepsis and sclerema in study subjects: In the present study majority 30 (71.43\%) had EOS and 12 (28.57\%) had LOS. All the study subjects who had exchange blood transfusion developed sclerema. Pugni, $L$ et al. (2016) in their study reported that newborns who underwent exchange transfusion $54 \%$ had early onset of sepsis and $46 \%$ had late onset of sepsis [21].

Duration of mean hospital stay days is $11.73 \pm 7.48$ days. Those who died had a mean duration of hospital stay was 6.5 days and those who survived had 18.7 days. Similarly the median duration of days in hospital was 11 days. In our study out of 42 study subjects $24(57.14 \%)$ have died and 8 $(42.86 \%)$ were discharged after exchange transfusion treatment. Of those who died 15 $(62.5 \%)$ were preterm and of those discharged 10 $(55.6 \%)$ were term neonates $(p=0.349)$. Outborn neonates more died as compare to inborn though this was also not significant $(p=0.133)$. Neonates with exchange transfusion who had 2-5 days of antibiotic had more death $13 / 24(54.16 \%)$ as compared to $6-8$ days $8 / 24(33.33 \%)$ and it was statistically significant $(p=0.000)$.

Neonates who stayed for a fewer number of days in hospitals had more dying as compared to those who stayed for longer duration and this was also statistically significant $(p=0.000)$. Morality in $2-5$ days and 5-10 days of hospital duration was $100 \%$ and in more than 10 days it was $16.67 \%$. Vain NE et al (1980) study the role of exchange transfusion in the treatment of severe septicemia. Ten critically ill newborn infants presenting with septicemia were treated with exchange transfusions. Seven of the ten $(70 \%)$ infants showed immediate improvement and ultimately survived [14]. Bossi et al. (1981) study the role of exchange transfusion for severe neonatal septicemia. They treated 35 neonates with severe sepsis, 22 of them treated with ET, and 13 with standard therapy alone.

The survival rate was similar between the two groups (ET, $54.5 \%$ vs. ScT, $53.8 \% ; p=$ No Significant). [22] Gross S.J. et al (1982) reported from a controlled trial, that the mortality rate was the same among those who received ET and those who did not receive it [23]. Dalvi $R$ et al (1991) study the exchange transfusions in neonatal sepsis. The mean time for recovery following ET was 19.6 +/- 12.4 h (range: 1-48 h).
The overall survival was $77.4 \%$ and the survival rates for LBW and non-LBW infants were 73.6 and $68.2 \%$, respectively, however, the difference was not statistically significant [24]. Exchange transfusion may thus be an effective and safe therapeutic modality for severe neonatal sepsis. Mathur NB et al (1993) study the effect of exchange transfusion in neutropenic septicemic neonates. Mortality was $35 \%$ in the study group and $70 \%$ in the controls. Gram-negative organisms accounted for $80 \%$ in the study group and $90 \%$ in controls [17]. Sadana S et al (1997) study the role of exchange transfusion in septic neonates with sclerema Mortality was $50 \%$ in the study group and $95 \%$ in controls [25].

Gunes T et al (2006) did a pilot study on Exchange transfusion or intravenous immunoglobulin therapy as an adjunct to antibiotics for neonatal sepsis. There were nine deaths $(27 \%)$ in the IVIG group, seven $(21 \%)$ in the ET group and nine $(41 \%)$ in the control group $(p>0.05)$ [19]. In a similar study Aradhya AS et al (2015) in Chandigarh reported that the primary outcome of mortality by 14 days from enrollment was observed in 14 (34\%) neonates in the DVET group in comparison to $18(42 \%)$ in the ST group, Similarly, early mortality (mortality by 7 days) as well as mortality by discharge showed a trend towards reduction in the DVET group in comparison to the ST group. No significant difference could be observed in the time to mortality. The median duration of stay days in hospital was 25 days [20].

Pugni, L et al. (2016) reported their 10 years' experience of exchange transfusion in the treatment of neonatal septic shock. The mortality rate was $36 \%$ in the ET group and $51 \%$ in the ScT group ( $p=$ $0.16)$. A multivariate logistic regression analysis, controlling for potentially confounding factors significantly associated with death (gestational age, serum lactate, inotropic drugs, oligoanuria), ET showed a marked protective effect (Odds Ratio $0.21,95 \%$ Confidence Interval: $0.06-0.71 ; p=$ 0.01 ). The lack of observed adverse events should encourage the use of this procedure in the treatment of neonates with septic shock [21]. Verma $A$ et al (2020) did a retrospective observational study on the role of DVET in severe neonatal sepsis.

There was a significant reduction in mortality in the intervention group $(57 \%$ vs. $71 \%(p=.004)$. They concluded that in neonates with severe sepsis, DVET may be a useful adjunct therapy. 
It may reduce mortality and is a safe procedure in severely sick and septic neonates [26].

In our study out of 36 culture-positive samples 15 $(41.7 \%)$ were discharged after treatment and 21 $(58.3 \%)$ have died. Of 36 culture positives maximum of 10 were positive for Klebsiella, 8 for E.coli, 6 each for S. aureus and P. aeruginosa, 4 were positive for Acinobactor and 2 were positive for Enterococcus. Pugni, L et al. (2016) reported that in the exchange transfusion group of neonates out of 26 culture-positive samples,5 (10.6\%) were Grampositive organisms and $21(44.4 \%)$ were Gramnegative organisms. In Gram-positive organisms maximum were $S$. epidermidis and in Gramnegative organisms maximum were $P$. aeruginosa, E. coli and K. pneumonia [21].

In our study maximum $32 \quad(76.19 \%)$ had cardiovascular dysfunction, $28(66.67 \%)$ had respiratory system dysfunction and 11 (26.19\%) had renal system dysfunction. In a similar study Aradhya AS et al (2015) in Chandigarh reported that $88 \%$ of cases had cardiovascular dysfunction, $56 \%$ had Hematological dysfunction and 34\% had renal dysfunction [20]. Similarly Pugni, L et al. (2016) reported in their study that in $(96 \%)$ cases the respiratory system has some dysfunction, in (90\%) cases had CVS dysfunction and in (48\%) cases had renal system dysfunction [21].

\section{Conclusion}

The study showed that in study subjects who underwent exchange transfusion $57.14 \%$ died and $42.86 \%$ were discharged after exchange transfusion treatment. Of those who died around two-third were preterm also, outborn neonates more died as compare to inborn though this was also not significant. Before exchange transfusion all the newborns had sclerema and that improved in 55\% cases after exchange transfusion.

In the study $76.19 \%$ had cardiovascular dysfunction, $66.67 \%$ had respiratory system dysfunction and $26.19 \%$ had renal system dysfunction. On vitals except for blood pressure $(p=0.000)$ none of the vitals i.e. temperature, $P R$, Spo2, Random blood sugar had a significant mean difference in their mean value before and after exchange transfusion. Neonates who stayed for a fewer number of days in hospitals had more dying as compared to those who stayed for longer duration and this was also statistically significant.
In conclusion, a significant reduction of mortality in patients who underwent exchange transfusion, together with the no adverse effects observed, suggest that this procedure should be considered for the treatment of neonates with severe sepsis. Thus, it is a safe procedure in severely septic neonates with inherent potential for complications. One needs to exercise caution in selecting the neonate and the team, and take all the necessary precautions irrespective of the indication. The exchange transfusion must be performed only by experienced individuals at a perinatal-neonatal centre using both a cardio-respiratory monitor and pulse oximeter. The team should be ready to respond to any adverse event that may arise at any stage of the procedure.

\section{Author's contribution}

Dr. Rao B. N. conceived, conceptualized, supervised the study, and finalized the manuscript. Dr. Dewangan S. helped in protocol writing, conceptualization, data analysis, and finalized the manuscript. Dr. Singh V. K. the protocol, recruited patients, analyzed the data, and prepared the manuscript. The final manuscript was approved by all authors.

\section{Reference}

01. Liu L, Oza S, Hogan D, Chu Y, Perin J, Zhu J, et al. Global, regional, and national causes of under- 5 mortality in 2000-15- an updated systematic analysis with implications for the Sustainable Development Goals. Lancet. 2016;388(10063)30273035. doi: 10.1016/S0140-6736(16)31593-8 [Crossref][PubMed][Google Scholar]

02. Liu L, Johnson HL, Cousens S, Perin J, Scott S, Lawn JE, et al. Global, regional, and national causes of child mortality- an updated systematic analysis for 2010 with time trends since 2000. Lancet. 2012; 379(9832)2151-61. doi: 10.1016/S0140-6736 (12)60560-1 [Crossref][PubMed][Google Scholar]

03. Adkins B, Leclerc C, Marshall-Clarke S. Neonatal adaptive immunity comes of age. Nat Rev Immunol. 2004 Jul;4(7)553-64. doi: 10.1038/nri1394 [Crossref][PubMed][Google Scholar]

04. Kapur R, Yoder MC, Polin RA. Developmental immunology, In- Fanaroff AA, Martin RJ editor(s). Neonatal-Perinatal Medicine- Diseases of the Fetus and Infant. 7th Edition, St Louis- Mosby. 2002 [Crossref][PubMed][Google Scholar] 
05. Levy O. Innate immunity of the newborn- basic mechanisms and clinical correlates. Nat Rev Immunol. 2007 May;7(5)379-90. doi: 10.1038/nri2075 [Crossref][PubMed][Google Scholar]

06. Wynn J, Cornell TT, Wong HR, Shanley TP, Wheeler DS. The host response to sepsis and developmental impact. Pediatrics. 2010 May;125(5)1031-41. doi: 10.1542/peds.2009-3301 [Crossref][PubMed][Google Scholar]

07. Shane AL, Stoll BJ. Neonatal sepsis- progress towards improved outcomes. J Infect. 2014 Jan;68 Suppl 1;S24-32. doi: 10.1016/j.jinf.2013.09.011 [Crossref][PubMed][Google Scholar]

08. Klinger G, Levy I, Sirota L, Boyko V, LernerGeva L, Reichman B. Israel Neonatal Network, Outcome of early-onset sepsis in a national cohort of very low birth weight infants. Pediatrics. 2010 Apr;125(4)e736-40. doi: 10.1542/peds.2009-2017 [Crossref][PubMed][Google Scholar]

09. Stoll BJ, Hansen NI, Adams-Chapman I, Fanaroff AA, Hintz SR, Vohr B, Higgins RD. National Institute of Child Health and Human Development Neonatal Research Network, Neurodevelopmental and growth impairment among extremely low-birth-weight infants with neonatal infection. JAMA. 2004 Nov 17;292(19)2357-65. doi: 10.1001/jama.292.19.2357 [Crossref][PubMed] [Google Scholar]

10. Kermorvant-Duchemin E, Laborie S, Rabilloud M, Lapillonne A, Claris O. Outcome and prognostic factors in neonates with septic shock. Pediatr Crit Care Med. 2008 Mar;9(2)186-91. doi: 10.1097/PCC.0b013e31816689a8 [Crossref] [PubMed][Google Scholar]

11. Prod'hom LS, Choffat JM, Frenck N, Mazoumi M, Relier JP, Torrado A. Care of the seriously ill neonate with hyaline membrane disease and with sepsis (sclerema neonatorum). Pediatrics. 1974 Feb;53(2)170-81. [Crossref][PubMed][Google Scholar]

12. Xanthou M, Xypolyta A, Anagnostakis D, Economou-Mavrou C, Matsaniotis N. Exchange transfusion in severe neonatal infection with sclerema. Arch Dis Child. 1975 Nov;50(11)901-2. doi: 10.1136/adc.50.11.901 [Crossref][PubMed] [Google Scholar]
13. Töllner $U$, Pohlandt $F$, Heinze $F$, Henrichs $I$. Treatment of septicaemia in the newborn infantchoice of initial antimicrobial drugs and the role of exchange transfusion. Acta Paediatr Scand. 1977 Sep;66(5)605-10. doi: 10.1111/j.1651-2227.1977. tb07955.x [Crossref][PubMed][Google Scholar]

14. Vain NE, Mazlumian JR, Swarner OW, Cha CC. Role of exchange transfusion in the treatment of severe septicemia. Pediatrics. 1980 Nov;66(5)6937. [Crossref][PubMed][Google Scholar]

15. Lemos L. Exchange transfusion in treatment of sepsis. Pediatrics. 1981 Sep;68(3)471-2. [Crossref] [PubMed][Google Scholar]

16. Sadana S, Mathur NB, Thakur A. Exchange transfusion in septic neonates with sclerema- effect on immunoglobulin and complement levels. Indian Pediatr. 1997 Jan;34(1)20-5. [Crossref][PubMed] [Google Scholar]

17. Mathur NB, Subramanian BK, Sharma VK, Puri RK. Exchange transfusion in neutropenic septicemic neonates- effect on granulocyte functions. Acta Paediatr. 1993 Nov;82(11)939-43. doi: 10.1111/j.1651-2227.1993.tb12604.x [Crossref] [PubMed][Google Scholar]

18. Tarnow-Mordi W, Isaacs D, Dutta S. Adjunctive immunologic interventions in neonatal sepsis. Clin Perinatol. 2010 Jun;37(2)481-99. doi: 10.1016/j.clp.2009.12.002 [Crossref][PubMed] [Google Scholar]

19. Gunes T, Koklu E, Buyukkayhan D, Kurtoglu S, Karakukcu M, Patiroglu T. Exchange transfusion or intravenous immunoglobulin therapy as an adjunct to antibiotics for neonatal sepsis in developing countries- a pilot study. Ann Trop Paediatr. 2006 Mar;26(1)39-42. doi: 10.1179/146532806X90592 [Crossref][PubMed][Google Scholar]

20. Aradhya AS, Sundaram V, Kumar P, Ganapathy SM, Jain A, Rawat A. Double Volume Exchange Transfusion in Severe Neonatal Sepsis. Indian J Pediatr. 2016 Feb;83(2)107-13. doi: 10.1007/s12098-015-1841-0 [Crossref][PubMed] [Google Scholar]

21. Pugni L, Ronchi A, Bizzarri B, Consonni D, Pietrasanta C, Ghirardi B, et al. Exchange Transfusion in the Treatment of Neonatal Septic Shock- A Ten-Year Experience in a Neonatal Intensive Care Unit. Int J Mol Sci. 2016 May 9;17(5)695. doi: 10.3390/ijms17050695 [Crossref] [PubMed][Google Scholar] 
22. Bossi E, Meister B, Pfenninger J. Exchange transfusion for severe neonatal septicemia. Pediatrics. 1981 Jun;67(6)941. [Crossref][PubMed] [Google Scholar]

23. Gross SJ, Filston HC, Anderson JC. Controlled study of treatment for disseminated intravascular coagulation in the neonate. J Pediatr. 1982 Mar;100(3)445-8. doi: 10.1016/s00223476(82)80457-5 [Crossref][PubMed][Google Scholar]

24. Dalvi R, Rao S, Rangnekar J, Fernandez A. Exchange transfusions in neonatal sepsis. Indian Pediatr. 1991 Jan;28(1)39-43. [Crossref][PubMed] [Google Scholar]
25. Sadana S, Mathur NB, Thakur A. Exchange transfusion in septic neonates with sclerema- effect on immunoglobulin and complement levels. Indian Pediatr. 1997 Jan;34(1)20-5. [Crossref][PubMed] [Google Scholar]

26. Verma A, Pandita A, Gupta G, Naranje KM, Singh A. Role of DVET in severe neonatal sepsis in an era of high antibiotic resistance- a retrospective observational study. J Matern Fetal Neonatal Med. 2020 May 27;1-6. doi: 10.1080/14767058.2020.1771303 [Crossref] [PubMed][Google Scholar] 